\title{
Global Leadership Competence: The Intelligence Quotient of a Modern Leader
}

\author{
Dr. Kerri Heath \\ Assistant Vice Chancellor \\ Pepperdine University \\ Graduate School of Education and Psychology, \\ Dr. Lene Martin \\ Communications Consultant \\ Amgen Inc. \\ Dr. Linda Shahisaman \\ International Relationship Manager \\ HSBC Bank
}

\section{Introduction}

What makes a great leader? This age-old question has led to many discussions and debates among scholars and ultimately the development of many leadership theories. The requirements for leadership have vastly changed in a short amount of time due to globalization and technology. As leadership has evolved, a new set of competencies are now required by leaders who want to influence on a global scale. This article will explore leadershipframeworks which have developed over the past few decades by thought-leaders to equip leaders for the modern age. The research being summarized is not original; however it is collected and presented in a cohesive way that is unique and timely. The authors will leave the readers with suggestions for future studies, and predictions about the future of global leadership competency.

Global leadership theories have a lot to do with the globalization of the world (Friedman, 2007). One of the main theories of global leadership is based on the idea of intellectual leadership (Young, 1991). There has been much research in the study of successful leaders internationally and some of the research began with the Global Leadership and Organizational Behavior Effectiveness (GLOBE) program that studied culture and leadership in 62 countries (House, Hanges, Javidan, Dorfman, \& Gupta, 2004). The researchers found that leaders have certain attributes that may lead to their success or failure in organizations. For example, certain sensitive situations such as language barriers and communication issues may hinder a leader's performance. Also, in some cultures certain attributes of the leaders were seen as a strength, while in other cultures these attributes were seen as a weakness. For instance, assertiveness and individualism were seen as unsuccessful ways of communication in somecultures.

The GLOBE study (House et al., 2004) went into detail discussing the main characteristics that effective leaders had, which included charismatic and transformational attributes. These qualities also included having foresight, willingness to encourage staffand 
coworkers, great communication skills, trustworthiness, positive attitudes, strong presence, and confidence. The charismatic attributes varied among the different types of cultures andincluded enthusiasm, risk orientation, ambition, humility, sincerity, and sensitivity. According to this study, leadership styles need to always be adjustable depending on the situation. Each situation calls for a different leadership style. Being culturally sensitive to these distinct cultures was the most crucial attribute needed from a leader in a global economy (House et al., 2004).

According to Young (1991), leadership plays a significant and complex role in the success or failure of institutional bargaining processes which largely define international regimes and arrangements in international society. There are three forms of leadership that are involved in creating or changing international institutions and they include: structural leadership, entrepreneurial leadership, and intellectual leadership. Having solid leadership does increase the chances of success in completing contracts with other international institutions. If someone wants to clearly understand the structure and politics in an international society, it would be beneficial to increase their efforts in studying and analyzing the activities of individuals in exemplary leadership roles. Leadership does involve the main ideology of most politics; yet, even with the increase of leaders in international societies, it has caused, in some cases, confusion rather than clarity.

Successful leaders often have qualities such as passion, vision, knowledgeable understanding of the industry, the ability to think critically, perspective, adaptability, and continual learning. Leaders must incorporate strong integrity where subordinates are able to trust them. They must continually express the expectation to their followers when a transformation takes place (Olson, 2009). The changes in speed of communication and exchange, the growth of networks used, and the increase of the volume of trade have all altered the way organizations are effective and efficient (Smith \& Doyle, 2002). In order for organizations to thrive, they must have great leaders. The evolution of what makes a great leader began with the common notion of intelligence (IQ), but a more robust understanding has emerged, and in fact, there are many intelligence competencies now requiring attention in order to be a successful global leader. To start, it is important to understand the use of and transition from what we know as intelligence.

Intelligence Quotient (IQ). Discussions about what makes a great leader are not new. The western enlightenment tradition valued the intelligence of a leader as measured by his or her IQ (attributes such as analytical, logical, and reasoning skills). This was widely accepted as the criteria for leadership competency in western business research until the 1990s. This helped organizations to identify and select a leader based on intelligence. Leaders were able to function this way, but organizations did not thrive under this type of leadership.

It is likely that every person knows intelligent people with very high IQ scores who still cannot lead or influence a culture. They may make decisions in a hierarchical fashion, but there is much to be gained when it comes to connecting with people, building a team, and excelling at customer service or employee retention. This then led to additional research on what truly makes a great leader.

Emotional Intelligence (EQ). In 1995, Daniel Goleman wrote a book titled Emotional Intelligence: Why it can matter more than $I Q$ which was groundbreaking and redefined what it 
meant to be "smart." This book became a bestseller and created a new dialogue about intelligence. Goleman hypothesized that IQ was only the tip of the iceberg - emotional intelligence was a much larger, more important piece of the puzzle.

In 1998, Goleman wrote a book titled Working with Emotional Intelligence and published an article in the Harvard Business Review titled "What Makes a Leader?" that transferred these findings to the discourse on leadership, and the rest is history. Leadership theorists grasped onto this concept and it was no longer acceptable for organizations to solely consider IQ as a reliable source for identifying future leaders. Emotional intelligence, which is divided into five components, was explained as an essential leadership tool for identifying and developing great leaders. EQ is comprised of personal competence (self-awareness, self-regulation, and motivation), which determine how we manage ourselves, and social competence (empathy and social skills), which determine how we handle relationships.

Self-awareness. Goleman explains that emotionally intelligent people have a tremendous amount of self-awareness (1985). Self-awareness is the ability to recognize and understand your moods, emotions, and drives, as well as their effect on others. As the great philosopher Aristotle said, "Knowing yourself is the beginning of all wisdom." A leader who has self-awareness is able to describe both their strengths as well as recognize the blind-spots they may have. They are able to give a realistic self-assessment which gives everyone around them an advantage. It is harder to build a great team around a leader who lacks self-awareness because they do not recognize the strengths they need in others to complement their own and vice versa.

It can be frustrating to work under a leader who has not mastered this function of EQ. If your boss thinks of him or herself as patient yet he or she is always losing his or her temper, team members can question a leader's capability to lead. However, if a leader shows self-awareness with authenticity and signs of self-deprecating humor, trust is gained. Leaders with self-awareness tend to exude greater confidence in the workplace.

Self-regulation. Emotionally intelligent leaders have the ability to self-regulate. This gift allows a leader to control or redirect disruptive impulses and moods. Leaders with high EQ have the propensity to suspend judgment and to think before acting. This is so valuable to team members who can then approach the leader with information and expect a cool, calm response.

Motivation. Leaders with higher EQ levels also demonstrate greater motivation. They have a passion to work for reasons that go beyond money or status. They are motivated to pursue goals with energy and persistence. This strong drive to achieve and create meaningful experiences leads to organizational commitment and optimism in the face of failure. Leaders who are only working for a title or position are not typically strong in EQ and leadership.

Empathy. Empathy is the ability to understand the emotional makeup of other people. This skill allows leaders to place themselves in the shoes of others, and treat people according to their emotional reactions. This is a sign of emotional intelligence and 
can create a strong connection with clients and customers, as well as expertise in building and retaining employee talent. Empathy is also a sign of cross-cultural sensitivity.

Social skills. Finally, emotional intelligence includes social skills, or the proficiency in managing relationships and building networks. People with strong social skills are able to find common ground and build rapport. This may lead to excellence in building and leading teams and great effectiveness in implementing change.

Cultural Intelligence (CQ). Cultural intelligence refers to an ability to interact effectively with people of different cultures (Ang \& Van Dyne, 2008). According to the Cultural Intelligence Center, "CQ is a person's ability to function effectively in situations characterized by cultural diversity" (Montgomery, 2011). Developing cultural competence results in an ability to understand, communicate with, and effectively interact with people across cultures. CQ is comprised of four components: awareness of one's own cultural worldview; one's attitude towards cultural differences; one's knowledge of different cultural practices and worldviews; and, one's cross-cultural skills (Gallagher-Louisy, 2013). Demonstrating CQ is about knowing one's own ethnic/cultural heritage and celebrating it. It is also about understanding that everyone has an ethnicity and a culture. High levels of CQ allow us to deepen our awareness of the trends in our own culture and not hold them as the standard, but instead become aware of the biases that they may create for us.

Leaders with high levels of CQ are champions for cultural competence in all environments and advocates for equality. Showing signs of genuine curiosity and being interested in cultural differences are earmarks of this quality. With CQ, there is an appreciation for the complexity of cultural differences. One of the more difficult aspects of CQ is learning to weigh personal values alongside other cultural perspectives so as to make ethical judgments where cultural differences are indeed considered. According to David Livermore, author of Leading with Cultural Intelligence, "It's less about becoming an expert about every culture and more about developing the overall capability that allows you to become effective and respectful in any cultural situation" (Montgomery, 2011).

In the realm of management and psychology, cultural intelligence is a term and theory that strives to describe the impact that diverse cultural identities have on an individual's behavior, and how effectively the organization engages in different environmental settings. There are three aspects in which cultural intelligence arises: cognitive; physical; and, through motivational means. These traits allow an individual to acquire a high sense of cultural intelligence in the context that is needed. The cognitive aspect is developed through the mind by understanding one's own culture and cultural diversity. The physical aspect is developed through the body by uncovering one's sensory environment and body language. The motivational aspect is developed through one's emotions and by receiving rewards and strengths from one's success. Cultural intelligence is measurable through a scaled system where individuals that have high cultural intelligence are much more successful by working in diverse environments, whereas individuals with low cultural intelligence are much more ineffective (Earley \& Mosakowski, 2004). 
Since there are many variations of cultural intelligence, the notion of intercultural competence becomes important. In order for one to understand culture, one needs to become knowledgeable by studying the beliefs, customs, and norms of foreign cultures. However, training in these cultures may never fully educate an individual because every individual's attitude in the culture is different. With one's body, one needs to understand how demeanor and body language can affect situations. This can mean anything from the way one shakes hands or orders food, to how one can imitate customs of the host culture. One may need to adopthabits and mannerisms to truly identify with the culture at hand. When an individual accomplishes these actions, people are more prone to trust and listen to the individual. Concerning an individual's heart, humility is very important. Also, confidence is crucial because if individuals do not believe in themselves, it is very difficult for others to believe in them (Earley \& Mosakowski, 2004).

Cultural intelligence can be vital in cross national work, mergers, and project groups. In cross national work, organizations rely on collaboration with other countries to apply change. In this situation, an organization needs to prevent conflicts and misunderstandings in every aspect. A culturally sensitive leader will understand that he or she needs to allow his subordinates to study the strategic background of cross national work and the differences related to the culture at hand. The cultural background of the international alliance must be studied. Individuals need to know how to establish good communication with key managers and subordinates. Mergers are complicated because synergy needs to be accomplished in a sometimes hostile environment. An effective leader will create planning procedures and strategies to establish a common understanding within cultures. This will allow for the transition of both organizations to flow much more smoothly, and then a common company culture can be created through shared beliefs and a shared history of the organization (Plum, 2007).

Culturally intelligent leaders understand that it takes time for a new culture to be deemed uniform. Project groups are being used more and more to encourage innovation, and many of these groups must seek to obtain synergy before conflicts occur. Cultural misunderstanding can occur and managers need to be aware of the differences between the individuals in the group to help to prevent conflict and enhance innovation. The growth of CQ occurs when, by reflection, the group learns what is and what is not working. All issues should be addressed upfront before a project takes flight and becomes successful (Plum, 2007).

Moral Intelligence (MQ). Moral intelligence (MQ) is a leadership intelligence competency that prescribes leading with the four core principles of integrity, compassion, responsibility, and forgiveness. It is suggested that practicing moral intelligence improves the success of a leader and therefore the organization, which then creates greater value for those connected to the organization, including employees, shareholders, and communities. For example, the principle of integrity may build trust amongst the employees. In addition, the principle of compassion may attribute to the retention of its workforce. Furthermore, the principle of responsibility may create inspiration. Finally, forgiveness may encourageinnovation (Kalman, 2011).

Moral intelligence in a changing society, or differing societies, may be a challenge to master. It may prove difficult to distinguish between what is appropriate and what is not. A 
person may deem a certain situation or action as inappropriate, but in other situations or societies it may be appropriate, it simply depends on what lens one is using. As leaders, it is important to understand the differences between varying situations and meanings. Leaders may risk being seen as moral hypocrites if they do not understand the concept of certain actions and behaviors. It is important for leaders to be morally intelligent and aware so as to not compromise one's moral terms or hinder moral growth (Sherman, 2015).

According to psychiatrist, author, professor, and one of the world's most prominent moral visionaries, Robert Coles states, "morality is not just niceties, or theoretical, or a side issue. It is the central issue of our existence, the factor that defines the quality of our lives as human beings" ("Robert Coles and the Moral Life," 2010). Moral intelligence for a leader is crucial, but it goes beyond whether one is acting morally or not, it proposes results to which a leader and the organization may thrive both in the public and private spheres. People have a natural inclination towards learning moral principles; however, a work environment which is nurturing towards learning these skills is necessary (Kalman, 2011). While working toward behavior change is important, a leader that encourages a learning environment is vital (Kalman, 2011). Executives often lead through skills formed from core business training, therefore leading through integrity, compassion, responsibility, and forgiveness must be practiced as any other skill to be effective.

Tactical examples of leading with moral intelligence may include the following: offer to a subordinate to begin a meeting with his or her agenda first; truly listen as opposed to talking to a team; and, be respectful towards employees as humans as well as professionals (Kalman, 2011). Additional tips for successfully leading with moral intelligence includes accepting responsibility, making less excuses, avoiding little lies, communicating respect, showing sympathy, practicing acceptance, and being tolerant of others' shortcomings. Forgiveness is less about how one relates to others and more about how one relates to oneself. In other words, others will treat you the way you treat yourself. Therefore, critical components to moral intelligence consist of being honest, maintaining integrity, and keeping commitments (Jensen, 2012).

Digital Intelligence (DQ). The digital age now requires new competencies of leaders through the fluency of technology. Those who have been born in the digital age are now called digital natives and are "native speakers" of technology, e.g., computer programs and software, videos, video games, web pages and websites, digital audio, social media, digital media, and other online mediums. Those who were able to exist, operate, and lead in this world prior to the integration of technology are called digital immigrants and are now learning a new digital language which seems foreign (Prensky, 2001).

In his article, "Digital Natives, Digital Immigrants," educational consultant Prensky (2001) coined the term digital native, which explains the contemporary decline in American education due to the failure of educators to understand the needs of modern students. His article explained that the arrival and fast dissemination of technology in the last decade of the 20th century had shifted the way that children think and process information, making it difficult for students to excel using outdated teaching methods. Students raised in a digital, media-saturated world, require a media-rich learning environment to hold their attention (Prensky, 2001). A 
trendier alternative has been proposed which refers to the Digital Visitor and Resident in regards to the various ways individuals engage with digital technology.

Whether you are a digital native or digital immigrant, you will need to be digitally intelligent if you are to lead in this new age. Digital intelligence (DQ) consists of four key principles: understanding the reasons to use technology, including its strengths, opportunities, and advantages; knowing what types of technology are available, what the options are, and the ability to choose the right tool for the right purpose; understanding how the technology works and having the ability to apply the technology in effective ways; and, developing the judgement to know when technology should be used, when it is going to benefit, and when it is going to cause challenges (Waller, 2016). It is also important to understand that having good judgement when exercising digital intelligence is critical, but good judgement is primarily created through the development of both ability and experience (Waller, 2016).

A leader or organization may be competent in technology but may fail to exercise good judgement, i.e., when or how it is appropriate to use specific technology capabilities. It is when ability is combined with diverse experience that a sound decision may be reached, and this also includes the ability to know alternatives. Developing digital intelligence is about building the knowledge and practicing the skills that will allow us to understand new technologies as they emerge, in addition to identifying opportunities and managing risks. Digital intelligence is also a transferable intelligence competency, meaning it is relevant to our personal and professional lives. In our global community, digital intelligence is important as it dictates how we may relate to each other (Waller, 2016).

A final consideration that demands attention is the importance of digital security, especially as we steadfastly evolve into a global society dependent upon technology and the increased value placed upon the information it transfers and stores. Digital tools are only as successful as its security capabilities to help manage, protect, and sustain its purpose. Therefore, in addition to the established four principles of DQ revolving around judgement, ability, and experience, digital intelligence must consider the technical aspects as well as human practice impacts to security in the digital age.

Gender Intelligence (GQ). Gender intelligence (GQ) evolved from the early idea that gender balance is achieved through viewing both genders as identical. However, it was discovered that equalizing the numbers does not lead to gender balance. While treating everyone the same may help to eliminate bias, it does not result in gender balance. The solution is not about eliminating differences, but rather learning how to recognize, value, and leverage those differences. In order to do this, it is important to understand and appreciate the natural talents that both men and women have to offer ("Gender Intelligence Group," 2013). Exercising gender intelligence as a leader within an organization may secure the best talent, lead to better decisions and strategies, create better products and services, and achieve heightened financial results. Therefore, it is suggested that practicing gender intelligence as a leader and organization leads to economic benefits and global competitiveness ("Gender Intelligence Group,"2013).

Barbara Annis (2014) wrote the book Gender Intelligence: Breakthrough Strategies for Increasing Diversity and Improving Your Bottom Line with Dr. Keith Merron, which represents 
the culmination of twenty-seven years of gender-based research and global practice that uniquely apply cutting-edge brain-based research to the workplace. This book offers the mindset and systemic changes that organizations need to transform their culture and bridge the gap between men and women at all levels of leadership and management. As a result of gender intelligence, leaders will create more inclusive and productive organizations (Annis \& Merron, 2014).

Despite decades of gender laws that address quotas, diversity training, affirmative action, and legal expenses toward equalizing pay and working conditions between the sexes, a glass ceiling remains in place for women. As efforts to treat people the same regardless of gender has been attempted, equality is yet to be realized. Annis and Merron (2014) surveyed over 100,000 men and women across dozens of Fortune 500 companies to provide a comprehensive understanding of the forces that perpetuate gender inequality. They conclude that "great minds think un-alike" and that women and men should work together to complement each other's strengths in the workplace as opposed to a "gender-blind" approach which treats both genders the same (Annis \& Merron, 2014). They suggest that women and men should learn to "work" and "win" together.

Global Intelligence (GQ). Global intelligence (GQ) is a leadership competency that describes how to be a more successful global leader, and it appropriately summarizes the common aspects and benefits of emotional intelligence, cultural intelligence, moral intelligence, digital intelligence, and gender intelligence, specifically the importance of self-awareness. As the world becomes more connected with the rise of social media and technology, there is a need for leaders with high EQ and high self-awareness who relate personally to their organization's people. Leaders need to celebrate diversity, know global issues, and have empathy and compassion (Caprino, 2015).

Bill George (2015), author of Discover Your True North, states that a global leader is transparent, authentic, genuine, builds trust, shares a clear vision, encourages diversity, empowers teams, aligns people to the organization's mission and values, and recognizes that all the constituencies of an organization must be served, e.g., shareholders, customers, employees, suppliers, and the community (Caprino, 2015). Successful global leaders must practice and master self-awareness to know their own stories - and this may be achieved through selfreflection and honest feedback. Once leaders are familiar with their own stories, they may know their own strengths, acknowledge their own weaknesses, exercise humility, model integrity, and lead with confidence (Caprino, 2015).

Having an effective global leader is a great competitive advantage to have within an organization. Also, having leaders with an understanding and ability to work in a global environment is rare and valuable within an organization. In turn, effective global leaders are the ones who are involved with the training and development of competencies, such as cultural intelligence. There are two ways that a leader may create a cultural competitive advantage: through didactic programs or sparingly used face to face cultural experiences. Didactic programs are training classes that are administered either through a third party or in-house to receive the cultural training that they need. These training courses involve virtual training modules, including insight on key behavior or personality traits needed to work within a global environment. Exposing leaders to the culture first-hand may mean either living in the country or 
experiencing short-term international assignments that involve day to day communication with the foreign culture (Ng, Van Dyne, \& Ang, 2009).

Recommendations for Future Studies. As society evolves and the demands of leadership continue to shift, researchers will continue to explore additional competencies that are required for leadership. It is difficult to predict what will come and what will be needed for future leaders to succeed; however, there are a few studies underway that will, no doubt, add rich data to this conversation.

Research is currently being collected, but additional work needs to be performed around generational intelligence, which is the ability of a leader to understand and work with various generations (e.g., baby boomers, gen x, millennials, etc.). There are a lot of modern issues that leaders may prepare for with this type of intelligence. As indicated, studies are being conducted in this area, but additional data analysis is needed.

Shirzad Chamine (2012) wrote a book titled Positive Intelligence: Why only $20 \%$ of teams and individuals achieve their true potential and how you can achieve yours. Positive intelligence is the science and practice of developing mastery over your own mind so you can reach your full potential for both happiness and success. Positive intelligence is groundbreaking research that exposes ten well-disguised mental saboteurs. According to Chamine (2012), nearly $95 \%$ of the executives who attend his Stanford lectures conclude that these saboteurs cause "significant harm" to achieving their full potential. With positive intelligence, you can learn the secret to defeating these foes.

An additional study revolves around creative intelligence. Bruce Nussbaum (2013) authored Creative Intelligence: Harnessing the Power to Create, Connect and Inspire. This book explores creative intelligence as a form of cultural literacy and a powerful method for driving innovation, problem-solving, and start-up capitalism (Nussbaum, 2013). This new approach frames problems in a way that devises solutions that are original and highly social.

\section{Conclusion}

Einstein's IQ was estimated to be 160, Madonna's was around 140, and Kennedy's was about 119, but IQ scores are no longer a strong prediction of one's professional achievement and success (Jensen, 2012). IQ tests were often used as a measurement of logical reasoning and technical knowledge, and it was often a necessity for climbing the business ladder. However, a high IQ is no longer an appropriate predictor for success, rather other intelligence competencies, e.g., emotional intelligence and moral intelligence, are proving to be a better indicator for executive competence and corporate success (Jensen, 2012).

Organizations tend to under-invest and underestimate the importance of developing and helping their leaders and employees to strengthen intelligence competencies outside of IQ. The ability and encouragement to learn and practice a variety of intelligence competencies allows for an individual to develop and master self-awareness. Self-awareness is a common thread amongst many intelligence competencies, proving to be a strong and essential trait of successful global leaders. The Carnegie Institute of Technology found that only $15 \%$ of an individual's financial 
success is due to technical knowledge, whereas $85 \%$ is due to personality skills such as the abilities to communicate, negotiate, and lead. It simply comes down to the idea that people are more likely to do business with people they trust (Jensen, 2012).

In our global and modern world, it no longer solely matters if a person received the best education or training from the best institution. An intelligent and rational person with a high IQ is a great asset, but it does not stand as the most important qualification. A person who has developed their skills in other intelligence competencies such as emotional intelligence, cultural intelligence, moral intelligence, digital intelligence, gender intelligence, and global intelligence (to name a few) may be just as successful (if not more successful) than a person with an impressive education or high IQ. An impressive IQ may help a person on an individual basis, but being skilled in other intelligence competencies may benefit an individual and others, including an entire organization and community. If an individual is able to master these under-rated, complex, and critical forms of intelligences, research shows that greater professional competence and capability may be achieved, and therefore greater success is possible (Jensen, 2012).

In summary, the quest for understanding leadership intelligence competency will continue for as long as the human mind is consumed with curiosity for how to grow and evolve. Researchers indulge the process of exploring leadership theory as they trace the ever-changing societal requirements for what it takes to lead. We will likely see many more studies unveil the competencies needed for leaders to survive and thrive in contemporary contexts. Some may tire of this type of work, but others never will.

\section{References}

Ang, S., \& Van Dyne, L. (Eds.). (2008). The handbook of cultural intelligence: Theory, measurement, and applications. New York, NY: M.E. Sharpe.

Annis, B., \& Merron, K. (2014). Gender intelligence: Breakthrough strategies for increasing diversity and improving your bottom line. New York, NY: HarperCollins Publishers.

Caprino, K. (2015). How much has our perception of great leadership shifted over the past decade and what has changed? Forbes / Leadership. Retrieved from http://www.forbes.com/sites/kathycaprino/2015/08/29/how-much-has-our-perception -of-great-leadership-shifted-over-the-past-decade-and-what-has-changed/\#4d672f39538e

Chamine, S. (2012). Positive intelligence: Why only $20 \%$ of teams and individuals achieve their true potential and how you can achieve yours. Austin, TX: Greenleaf Book Group Press.

Earley, C., \& Mosakowski, E. (2004). Cultural intelligence. Harvard Business SchoolReview, 82(10), 139-146.

Friedman, T. L. (2007). The world is flat. New York, NY: Farrar, Straus and Giroux. 
Gallagher-Louisy, C. (2013). Intro to crosscultural competence. Retrieved from http://www.slideshare.net/CathyGL/intro-to-crosscultural-competence

Gender Intelligence Group. (2013). What is gender intelligence? Retrieved from http://www.genderintelligence.com/what-is-gender-intelligence/

George, B. (2015). Discover your true north. Hoboken, New Jersey: John Wiley \& Sons, Inc.

Goleman, D. (1995). Emotional intelligence: Why it can matter more than IQ. New York, NY: Bantam Books.

Goleman, D. (1998). What makes a leader? Harvard Business Review, 76(6), 93-102.

Goleman, D. (1998). Working with emotional intelligence. New York, NY: Bantam Books.

House, R. J., Hanges, P. J., Javidan, M., Dorfman, P. W., \& Gupta, V. (2004). Culture, leadership, and organizations: The GLOBE study of 62 societies. Thousand Oaks, CA: Sage.

Jensen, K. (2012). Intelligence is overrated: What you really need to succeed. Forbes / Leadership. Retrieved from http://www.forbes.com/sites/keldjensen/2012/04/12/ intelligence-is-overrated-what-you-really-need-to-succeed/\#2ead03c26375

Kalman, F. (2011). Why moral intelligence must be part of leadership development. Chief Learning Officer. Retrieved from http://www.clomedia.com/2011/09/09/why-moralintelligence-must-be-part-of-leadership-development/

Montgomery, J. (2011). Teaching cultural intelligence could provide advantages in job market. Retrieved from http://www.huffingtonpost.com/2011/03/25/ cultural-intelligence-education_n_840660.html

Ng, K. Y., Van Dyne, L., \& Ang, S. (2009). From experience to experiential learning: Cultural intelligence as a learning capability for global leader development. Academy of Management Learning \& Education, 8(4), 511-526.

Nussbaum, B. (2013). Creative intelligence: Harnessing the power to create, connect and inspire. New York, NY: Harper Business Publishers.

Olson, D. A. (2009). Are great leaders born, or are they made? Frontiers of Health Services Management, 26(2), 27-30.

Plum, E. (2007). Cultural intelligence - A concept for bridging and benefiting from cultural differences. Retrieved from http://www.kulturelintelligens.dk/Cultural_ Intelligence_Plum.pdf

Prensky, M. (October 2001). Digital natives, digital immigrants. On the Horizon, 9(5), 1-6. 
Robert Coles and the Moral Life. (2010). Retrieved from http://www.mindful.org/robert-colesand-the-moral-life/

Sherman, J. E. (2015). Moral intelligence 101. Psychology Today. Retrieved from https://www. psychologytoday.com/blog/ambigamy/201512/moral-intelligence-101

Smith, M. K., \& Doyle, M. (2002). Globalization, the encyclopedia of informal education. Retrieved from www.infed.org/biblio/globalization.htm

Waller, S. (2016). The four elements of digital intelligence (DQ). Retrieved from http://www.simonwaller.com.au/blog/the-four-elements-of-digital-intelligence-dq/

Young, O. R. (1991). Political leadership and regime formation: On the development of institutions in international society. International Organization, 45(3), 281-308.

\section{Author Biographies}

Dr. Kerri Heath is a Midwestern native who currently lives in Los Angeles, California and works as the Assistant Vice Chancellor at Pepperdine University's Graduate School of Education and Psychology. Dr. Cissna-Heath has worked in higher education for over fifteen years and focuses her research agenda on leadership development, racial reconciliation, and women's issues. Dr. Heath is the author of two books on Women in Leadership and WorkFamily Integration.

Dr. Lene Martin is Norwegian-American and currently lives in Malibu, California working as a communications consultant in information technology and cyber security. With over fifteen years in the communications industry, she has experience with many top organizations such as Lockheed Martin Corp. and Amgen Inc. Lene holds master's degrees in communications and women's studies, a doctorate in organizational leadership, and her research agenda includes leadership, gender equality, work-life balance, and Norwegian culture.

Dr. Linda Shahisaman is Iranian-American and currently lives in Los Angeles, California working as an International Relationship Manager with HSBC Bank with customers in the Asia and Latin America territories. Her research interests include cultural intelligence and work-life balance, with a focus in helping women in South Asia achieve management positions. Sheholds a master's degree in business administration, and a doctorate degree in organizational leadership. 